\title{
Memória, genealogia e subjetividade em João Cabral
}

Éverton Barbosa Correia Universidade Federal da Paraíba

\begin{abstract}
Resumo: O poema "Autobiografia de um só dia" foi publicado inicialmente no livro A escola das facas, no início da década de 1980, quando o autor já era maduro e consagrado. Ali, João Cabral de Melo Neto descreve a circunstância de seu nascimento, debaixo de um "céu de gesso", em volta do aparato familiar. Interessa, pois, investigar como o autor constrói a ideia de céu, para que possamos relacionar o seu ideário religioso com as determinaçôes familiares, que passam a ser distintivas do seu lugar social. A partir dai, podemos vislumbrar como a matéria de sua expressão pode ser vinculada a seus traços estilisticos. Assim, abre-se a possibilidade de nos aproximarmos, tanto quanto possivel, dos aspectos subjetivos de sua obra, já que no poema em foco ele se expressa na primeira pessoa, fato absolutamente episódico na sua produção, que é marcada pela objetividade e pela terceira pessoa.

Palavras-chave: João Cabral de Melo Neto, Poesia brasileira moderna, Memória, Genealogia.
\end{abstract}

Quando do falecimento de João Cabral de Melo Neto, foi com grande surpresa que os seus leitores receberam a notícia; não por sua idade, uma vez que o autor beirava a casa dos oitenta e já se encontrava alquebrado 
pelo tempo, inclusive com a visão comprometida, a ponto de impedir a escritura de novos livros. Sua última publicação esparsa é datada de 1989, com o volume Sevilha andando e, depois disso, na reunião de 1994 pela Nova Aguilar sob o título de Obra completa, sob organização e prefácio da poetisa Marly de Oliveira. Naquela edição da Nova Aguilar, apareceu pela primeira vez Andando Sevilha, dedicado à organizadora do volume que era então sua esposa. Ela cuidava não só do poeta, mas também da veiculação, da projeção e da representação daquela obra junto a seu público leitor. O estranhamento com que os admiradores do poeta receberam as declarações dela sobre o marido no leito de morte ocorreu menos pela indiscrição que envolvia um sujeito polido e escorreito, que havia sido diplomata, do que pela incompatibilidade das informações divulgadas com o perfil que o poeta se empenhara em construir durante toda a vida, que incluía a figuração de um homem de princípios firmes, entre os quais constava o de ser ateu. Como, então, em seu último momento haveria de rezar o terço? A imagem de João Cabral com um terço na mão é algo muito distante do que seus leitores se acostumaram a identificar no poeta pernambucano. A informação ganhou relevo na medida em que foi confirmada por outros, próximos ao falecido, a exemplo de Ledo Ivo. ${ }^{1}$

Se a informação causa estranheza e nos desconserta a todos os seus leitores, é preciso reconhecer uma relação vívida e recorrente de João Cabral não somente com a morte, mas também, e sobretudo, com a ideia de uma divindade ou sentido de religiosidade, quer pensemos numa compreensão de vida após a morte ou numa religião específica. Tendo ele frequentado um colégio católico durante sua infância e adolescência, muitos são os seus depoimentos a respeito das impressões que tal colégio lhe causou e das influências que dele recebeu. Tanto é que, em alguns poemas, podemos também perceber não só referências aos maristas, mas reiteradamente à morte e ao inferno.

Havendo, pois, uma sucessão de imagens que se superpõem ao longo de sua produção, conviria flagrar um momento em que identificamos a obsessão pela morte, algum princípio religioso e o sujeito envolto numa circunstância tal, que, se não servir para produzir uma possibilidade de religação com o universo circundante, certamente servirá para dar uma dimensão da religiosidade que anima sua produção, já que, construindo deliberada e conscientemente suas composições, não lhe terá escapado a religiosidade

\footnotetext{
1 VASCONCELOS. João Cabral de Melo Neto, p. 95.
} 
nelas presente. A pretexto de circunscrever o problema, tomemos um poema publicado inicialmente no livro A escola das facas (1980), onde a circunstância de nascimento do poeta é narrada, conforme se segue:

"Autobiografia de um só dia"

A Maria Dulce e Luiz Tavares

No engenho Poço não nasci:

minha mãe, na véspera de mim,

veio de lá para a Jaqueira,

que era onde, queiram ou não queiram,

os netos tinham de nascer,

no quarto-avós, frente à maré.

Ou porque chegássemos tarde

(não porque quisesse apressar-me,

e se soubesse o que teria

de tédio à frente, abortaria)

ou porque o doutor deu-me quandos, minha mãe no quarto-dos-santos,

misto de santuário e capela,

lá dormiria, até que para ela,

fizessem cedo no outro dia

o quarto onde os netos nasciam.

Porém em pleno Céu de gesso, naquela madrugada mesmo,

nascemos eu e minha morte, contra o ritual daquela Corte

que nada de um homem sabia: que ao nascer esperneia, grita. 


\begin{abstract}
Parido no quarto-dos-santos, sem querer, nasci blasfemando, pois são blasfêmias sangue e grito em meio à freirice de lírios,

mesmo se explodem (gritos, sangue), de chácara entre marés, mangues.
\end{abstract}

O título do poema chama a atenção por duas razões: a primeira se deve ao vocábulo "só", que, anteposto a "dia", exerce exclusivamente sua condição de advérbio. Caso estivesse posposto a "dia”, o vocábulo provocaria uma ambiguidade indesejada e, pelo visto, de propósito evitada pelo autor, que o rejeita em sua função adjetiva. Assim, depurando o uso do vocabulário, o enunciado do título escapa à especulação de que naquele momento o sujeito estivesse sozinho, para especificar bem que sua autobiografia é de apenas um dia. E aqui chegamos à segunda curiosidade do texto, que reside no fato de assumirse efetivamente como autobiografia e de um dia somente. Esse dado curioso abre a possibilidade de esmiuçamento da vida do poeta e, por extensão, de sua subjetividade, contrariando a imagem que ele quis e construiu de si mesmo, durante muito tempo. A isso se acrescenta que a autobiografia que ele se propõe a fazer é de um dia apenas, como se ainda hesitasse perante a descrição de sua vida, inscrevendo-a num ponto bem preciso: o dia de seu nascimento. Neste caso, a descrição autobiográfica se esboça e se nega ao mesmo tempo, inclusive por ser feita em versos que narram o episódio de um dia. Ora, se a biografia de um sujeito pode ser circunscrita a um dia, isto pode indicar algum laivo de predestinação, assim como pode apontar também para a descrição da imagem que o poeta quer para si, amalgamada no lampejo de um instante. Dito de outra maneira, aquela outra imagem galvanizada - meio de pedra, meio de cristal que o poeta se empenhou em construir para si mesmo, durante bom tempo, a partir de agora parece ceder espaço a outra imagem que o poema encarna.

Como o poema traz várias referências particulares ao universo do poeta, incluindo aí uma sintaxe própria, convém examinar o enredo narrado, para passarmos a outros níveis de análise com maior segurança. O episódio pode, então, ser resumido assim: os pais do poeta, Luiz Antonio Cabral de Mello

2 MELO NETO. Obra completa, p. 439. 
e Carmem Carneiro Leão Cabral de Mello, residiam no Engenho Poço (herdado do avô paterno do poeta, seu homônimo), onde o ramo Cabral de Mello, em que encontramos o poeta, teve forte ascendência. Acontece que seu avô materno, Virgínio Marques Carneiro Leão, exigia que todos os seus netos nascessem não só na sua casa, mas no seu próprio quarto. Daí a palavra composta "quarto-avós" constante no poema. Esta casa era situada numa chácara de propriedade de seu avô materno, cujo nome era a Jaqueira, que dá nome atualmente a um bairro no Recife, já que o sítio não existe mais. O verso "veio de lá para a Jaqueira" informa, portanto, que sua mãe saiu do Engenho Poço - onde morava - para a casa do pai dela na cidade do Recife.

Aí chegando, a gestante foi alocada no quarto dos santos, já que a considerar a previsão do médico - o nascimento só se daria posteriormente. Diante da previsão, a futura mãe poderia circunstancialmente ficar no quarto de reza do casarão da Jaqueira, para que, no dia seguinte, começassem os preparativos com vistas à sua acomodação no quarto de seus pais, onde os seus filhos deveriam nascer, conforme as instâncias de seu pai. Ocorreu que, contrariando a previsão médica, naquela madrugada mesmo nasceu o rebento em hora e local imprevistos, soando gritos deslocados que ecoavam na maré do Capibaribe, onde estava plantada a casa de Virgínio Marques Carneiro Leão.

O episódio, ao que parece, repercutiu consideravelmente no seio familiar, haja vista que os irmãos mais novos do poeta não nasceram mais na casa do avô materno e que o acontecimento se converteu em capítulo importante da narrativa familiar, já que o poeta só pode ter travado conhecimento do episódio, que ainda hoje pode ser rememorado pelo seu irmão caçula, o importante historiador que é Evaldo Cabral de Mello, através de oitiva. Tendo, involuntariamente, rompido com o costume de uma família tradicional pernambucana, o poeta se opõe a ela quando diz: "Nascemos eu e minha morte / contra o ritual daquela Corte". Interessa destacar aí que toda família tradicional reivindica para si alguma nobreza, ao que podemos reputar a capacidade de figurar nalguma corte. E embora o poeta tivesse antepassados que figuraram na corte de D. Pedro II, notadamente pela linhagem dos Souza Leão, que se entronca com a dos Cabral de Mello, por um lado, e com a dos Carneiro Leão, por outro, não havia mais a necessidade de celebrar tal nobreza, já que sua existência soava algo remoto, do século anterior, e que, por conseguinte, já não repercutia vivamente naqueles anos da década de 1920. Tal nobilitação familiar fica ainda mais controvertida na medida em que também é possível identificar 
uma nobreza vinculada ao chão pernambucano e que, além de ser simbólica, não é portadora de títulos honoríficos: sua nobilitação é decorrente dos feitos que demarcam e consagram a história pernambucana. Ou seja, sendo simbólica esta nobreza - por não existir mais ou por nunca ter existido de fato -, muito mais simbólica haverá de ser a sua corte, com os seus respectivos ritos. Não havendo concretamente a corte, o ritual soa como o cacoete de uma nobreza que já não existia mais. Mas o mais curioso do dístico é que antes de nomear de maneira trânsfuga sua família como uma corte de rituais perdidos, o poeta afirma que aí nasceram ele e sua morte, como se estivessem os dois de mãos dadas, já naquele momento.

Ora, o nascimento é, como sabe toda gente, um evento único e singular, circunstanciado no tempo, e, portanto, muito distinto e distante da morte, a não ser nos casos de natimortalidade, que não é o do poeta, obviamente. Sendo assim, como podem estar justapostos e imbricados o nascimento do poeta e sua morte, que ocorreu quase oitenta anos depois? Podemos aventar a possibilidade um tanto mistificadora de que o evento de nascimento de um sujeito já traz consigo o seu correspondente último, que seria o seu falecimento. Ocorre que este não é um procedimento usual no contexto da produção do autor e estamos, evidentemente, diante de um poema muito elaborado, portador de uma série de dísticos que também se pautam pela elaboração, em menor escala. Reconhecendo que a elaboração também existe neste dístico, a tirar pelo que os substantivos "ritual" e "corte" nos evocaram, convém especular mais um pouco sobre a relação possível entre o nascimento do poeta e sua morte, que conjugam eventos distanciados no tempo - João Cabral é um poeta para o qual a referência é importante e sempre conta.

No contexto do poema, quando o poeta grafa "minha morte", só pode estar se referindo a uma dimensão simbólica da morte, já que ela, de fato, não ocorreria naquele instante. Porém, no momento de seu nascimento já estava anunciado tudo aquilo contra o que o poeta teria que se insurgir durante toda sua vida e que ali já estavam inscritos nos objetos a seu redor, que representavam sua negação mais lídima e vívida na atmosfera que o circundava e que estava às margens do Capibaribe. Rio que no dialeto da família era chamado de "a maré", tal como informa o verso do poema "Prosas da maré da Jaqueira", também publicado em A escola das facas, e que é atualizado neste poema aqui. Entre o curso do rio que margeava a casa de seu avô materno e o ritual inscrito no interior da vida familiar, alguma mediação precisava ser feita para a constituição 
do sujeito que viria a viver entre esses dois mundos: o de fora (o rio) e o de dentro da casa (o universo familiar). A morte passa, então, pelo cosmo familiar que desata, num mesmo cordão, uma série de ritos, dentre os quais os religiosos, que se traduzem nos objetos mais circunstantes, que, ao mesmo tempo em que permitem uma ligação do sujeito com o seu derredor, lançam-no na condição mais natural e crua, onde podemos identificar o sangue e o grito de suas blasfêmias que se opunham à freirice de lírios, constantes no penúltimo dístico: "pois são blasfêmias sangue e grito / em meio à freirice de lírios".

Se há neste momento do poema uma catolicização da natureza, na medida em que os lírios se assemelham a freiras ou à imagem que elas (as freiras) nos evocam, é preciso dizer que, antes disso, o poeta havia engessado o céu, a pretexto de circunstanciar o ambiente de seu nascimento, quando diz: "Porém em pleno Céu de gesso, / naquela madrugada mesmo, // nascemos eu e minha morte, / contra o ritual daquela Corte". Do par de dísticos, destaca-se o fato de que as únicas palavras grafadas em maiúsculas são "Céu" e "Corte". Sendo qualificada pela locução adjetiva "de gesso", a palavra "Céu" perde toda a magnitude indicada pelo uso da maiúscula, ao passo que a palavra "Corte", referindo-se a uma corte que não existe de fato, também contradiz a pompa que supostamente teria uma corte, o que também pode ser lido ironicamente, pelo uso da maiúscula, em sentido deslocado, tal como acontece com "Céu". Assim justapostas, as duas palavras ganham em evidenciação para esvaziar o significado do referente a que remetem, seja através de um céu engessado ou de uma corte depauperada por um ritual deslocado e perdido no tempo.

Se o ritual da corte era o objeto de sua profanação, o céu de gesso dava a ancoragem necessária àquela situação, envolta de lírios e santos, provavelmente, também de gesso. Aliás, a associação é bem lógica: de gesso os santos, logo o céu também seria de gesso. A propósito, valeria a pena lembrar que, antes dele, um antepassado seu já havia dado tratamento semelhante às imagens católicas. Refiro-me a seu tetravô e lexicógrafo Antonio de Moraes Silva, a quem o autor devotou um poema no mesmo livro que enfeixa sua "Autobiografia de um só dia”. Não deixa de ser curioso que o poeta que tinha evitado declarações subjetivas e, menos ainda, biográficas, no mesmo livro tenha se posto a escrever sobre personalidades históricas, como no poema "Abreu e Lima", e que, tal como no poema dedicado a seu ancestral, se refira ao título, ao nome e à vida do sujeito tratado. Mas como não é exatamente isso que acontece com o poema dedicado à sua própria vida, vejamos o que há em comum entre 
os tratamentos dados às imagens de dois dos literatos da mesma família (Cabral e Moraes), mas segundo a narrativa de um terceiro, Evaldo Cabral de Mello, irmão caçula do poeta:

O filólogo era verdadeiramente um homem sem religião. Não ouvia missa nem jejuava nos dias de preceito, impedindo sua mulher, filhos e escravos de o fazerem; mandava trabalhar os pretos nesses dias não só pela vantagem pecuniária daí decorrente, mas também 'por reputar a missa coisa inútil e irrisória'; alardeava jocosamente que ia mandar ordenar dois negros para o serviço da capela do engenho, a qual, aliás, relegava ao abandono [...]; consentia aos filhos brincarem com a imagem do menino Jesus nos braços de São José, arrastada pela bagaceira e, quando interpelado sobre tamanho desaforo, respondia que não se 'fizesse caso, que aquilo era uma calunga'.

A informação ganha relevo quanto mais considerarmos que a matéria de composição de João Cabral se faz, a um só tempo, histórica, geográfica e genealógica, porquanto consideramos o que houver aí de influência familiar na sua obra, seja pelo legado literário que herda, seja, ainda, pela celebração de um ritual insólito que se constrói em torno de sua figura. Por uma razão ou por outra, as determinações familiares inscritas na sua produção se constituem como um peso que ele tem de carregar e que, às vezes, repercute positivamente - como é o caso de Antonio de Moraes Silva - e às vezes não - como é o caso do ritual aludido. Mas como não é possível ao poeta, como a ninguém, separar o joio do trigo do que é herdado dos antepassados, ele incorpora ambas as dimensões. E se neste poema que ora abordamos fica evidente como problema a sua colocação no ambiente familiar, é preciso dizer que todas as agruras daí decorrentes adquirem feição histórica e geográfica. Pois é como circunstância histórica e geográfica que ele trata a sua genealogia e, por conseguinte, sua família nuclear também. Das marcas que constituem o poema analisado, é preciso dizer que nem Maria Dulce nem Luiz Tavares (constantes na dedicatória) são de sua família e, portanto, devem ter sido os amigos pernambucanos que partilharam com o poeta o assunto que deu ensejo à composição poemática.

Curioso, ainda, é notar que, ao descrever a biografia alheia no mesmo livro A escola das facas, o poeta grafa o nome do biografado no corpo do respectivo poema - tal como fez com Natividade Saldanha - ou, mais ainda,

3 MELLO. O nome e o sangue, p. 276. 
no corpo e no título do poema - tal como aconteceu com Moraes e com Abreu e Lima, mas não aplica o mesmo procedimento a si próprio. Ao invés, não há nome, prenome ou sobrenome que o distinga particularmente no corpo do poema, de modo que, se não soubéssemos de quem é o texto, sua autoria poderia passar incógnita, não fossem os expedientes formais, facilmente associáveis à sua expressão. A este respeito é preciso frisar que neste poema, tal como em outros nos quais identificamos a presença de um "eu", a subjetividade do autor se torna reconhecível pela forte incidência de formas pronominais que apontam para o sujeito estruturador do texto, quais sejam, o possessivo (minha) e os oblíquos (me, mim). Mais ainda, as formas verbais da primeira pessoa, tais como ocorrem no primeiro verso (nasci) e no nono (soubesse), deixam o sujeito oculto, já que o pronome pessoal do caso reto não comparece em nenhum dos dois casos. Mas há aí uma silente e gradual passagem do sujeito oculto na primeira pessoa do singular para a primeira pessoa do plural, que ocorre no sétimo verso (chegássemos) para se concretizar e se materializar através do sujeito que, na primeira pessoa, compõe o plural com sua morte, tal como informa o verso 19: "Nascemos eu e minha morte".

A curiosidade se aguça tanto mais, quanto mais percebermos que o aparecimento do 'eu' naquele livro é um evento único, embora não o seja no contexto de sua obra como um todo, já que podemos apontar algumas ocorrências do pronome pessoal nos livros anteriores a Psicologia da composição. Ao passo que, depois deste livro, somente no poema "Autobiografia de um só dia", coligido no livro A escola das facas, é que vamos encontrar outra incidência do pronome. Ou seja, após se tornar um poeta reconhecido, o autor se empenha em depurar de sua imagem contaminações biográficas, o que só voltaria a acontecer explicitamente em momento ulterior de sua produção, quando já está incorporado ao panteão dos grandes autores da literatura brasileira e até da língua portuguesa. Acresce ainda que, no momento de publicação deste poema, em que o autor se mostra na condição pronominal, na primeira pessoa do singular, ele já está beirando a casa dos sessenta, portanto, se trata de um momento de maturidade em que sua memória aflora quase que compulsivamente, o que fica evidenciado no contexto do livro A escola das facas como um todo, e que o poema analisado encarna de modo bem particular. Por tudo isso não podemos ignorar que estamos diante de um poeta que se fez grande pela ostensiva e deliberada negação do seu "eu", por mais contraditória que possa parecer a afirmação, haja vista que a poesia é por excelência o reino da subjetividade. 
Isso posto, após a constatação de que há um sufocamento da subjetividade ao longo de sua produção, há o reaparecimento de um "eu" demissionário numa circunstância particular de sua escritura, quando a especulação do passado familiar propicia a religação com o seu universo de origem, sob o filtro da memória que o ata a certa prática ritualística, carregada de religiosidade, com a qual o autor não lida pacificamente.

Por outra, poderíamos dizer que, quando o poeta se observa como objeto de uma circunstância precisa, em que os espaços circunstantes passam a caracterizá-lo - seja o engenho do pai ou a casa do avô e seus cômodos -, é que ele se permite ser visto como um sujeito. Sujeito que não é absolutamente individual, mas, ao contrário, se vê espelhado nos santos e devotos que o acompanham, no céu e no teto que o protege. É como parte de toda uma ambiência ao seu redor que aquele sujeito aparece, porque aí podemos visualizá-lo histórica e geograficamente enraizado no seio familiar, que aponta necessariamente para uma genealogia que desaparece no corpo do poema e na história, mas que lhe deu substância naquele momento, como sujeito histórico e como sujeito lírico.

E é bem verdade que o autor poderia ter escolhido um outro evento como sendo característico de sua história, fosse a vivência na Espanha ou a tomada de posse na Academia Brasileira de Letras, ou ainda, qualquer outro evento que conferisse alguma dignidade à sua figura, causasse alguma impressão ou simplesmente o apresentasse como um ser humano que despertasse algum interesse. Em vez disso, ele se apresenta como parte de um ritual esdrúxulo projetado a partir de seu possível nascimento, que, quando se dá, rompe com o cerimonial que devia consignar-lhe alguma pompa, na medida em que subscreveria - mesmo sem querer - a escrita daquele rito macabro, que atualizava a árvore genealógica que o acolhia e lhe servia de guarida. João Cabral rompe com aquele arremedo de cerimônia, radicalizando-o, quando nasce num outro local que não o programado e antes do dia e da hora previstos. Tudo isso interessa, porque dá a dimensão do indivíduo no contexto da coletividade representada pela sua família, que não é uma família qualquer, quer tomemos qualquer um de seus costados. No momento em que o sujeito historicamente situado naquele contexto genealógico rompe com o ritual familiar, rompe em alguma medida com a sua família. E foi assim que ele quis ser visto, sem o apoio da família e sem o apoio do respectivo ritual - de teor católico -, cruamente exibido em sua condição natural, entre sangue e gritos, entre marés e mangues, tal como foi o 
seu nascimento que adquire valor fundante à sua autoimagem, ao menos assim é a partir do que lhe contaram e se cristalizou em poesia.

Acontece que o episódio que deu impulso à narrativa familiar que chegou até o poeta se confunde e se justapõe a outras narrativas familiares, a exemplo da que identificamos noutros poemas do mesmo livro, tais como "Antonio de Moraes Silva", "Tio e sobrinho" ou "Menino de três engenhos". Este último poema, a depender da publicação, figura no livro A escola das facas - tal como consta na edição da Nova Aguilar de 1994 - ou no Crime na Calle Relator - tal como figura na publicação original e na segunda edição da Nova Aguilar de 2008. A informação serve para constatarmos que, assim como a obra do poeta se vale de fios narrativos que enredam uma narração familiar, também os seus leitores se valem de expedientes para credenciar tal ou qual leitura de sua obra, inclusive através de expedientes editoriais. Mas como estamos chegando, cada vez mais, a uma compreensão mais consequente e menos ortodoxa de sua obra, já é tempo de averiguar como tais narrativas se conjugam e se tocam, partindo, sobretudo, do que podemos identificar a partir dos próprios poemas.

Neste sentido, é oportuna a lembrança do poema "Descoberta da literatura", já que o poema "Autobiografia de um só dia" dialoga com outros poemas do livro A escola das facas que apontam para o universo familiar, que tem forte carga simbólica e, por isso, serve de índice para a demarcação do sujeito poético. Na medida em que o poema "Descoberta da literatura" narra uma experiência literária fundamental para a constituição do repertório do poeta, funciona como possível parâmetro da fusão entre sujeito e objeto que ele opera. Até porque neste poema o autor se transfigura a um só tempo em narrador e personagem, embora os verbos da narração estejam quase todos na terceira pessoa, tal como constatamos na parte do poema abaixo transcrita.

\footnotetext{
No dia-a-dia do engenho, toda semana durante, cochichavam-me em segredo: saiu um novo romance. E da feira de domingo me traziam conspirantes para que os lesse e explicasse um romance de barbante. Sentados na roda morte de um carro de boi, sem jante, ouviam o folheto guenzo,
} 
a seu leitor semelhante, com as peripécias de espanto preditas pelos feirantes.

A circunstância que se faz objeto da narração é a leitura de folhetos de cordel para trabalhadores de engenho de cana-de-açúcar. Acontece que o engenho era o de Luiz Antonio Cabral de Mello e o leitor era o seu filho João, que na época andava com os seus oito a dez anos. Foi assim que o autor travou contato com a literatura, em situação quase clandestina, haja vista que seu pai decerto não veria com bons olhos a relação do menino com os empregados. Se a circunstância foi capaz de fundar uma experiência que vai repercutir no autor que o menino viria a ser posteriormente, seja pela identificação com os tipos marginais - apesar de ser filho do engenho -, seja pela incorporação de uma modalidade métrica oriunda das bocas populares, ou ainda, de um vocabulário simples e direto que visava à comunicação imediata, o fato é que este poema serve de ótimo exemplo do modo como o autor fala de si mesmo, como se representa em perspectiva e como expressa sua subjetividade. Pois as palavras que identificamos no texto que nos conduzem a ele são as seguintes: o pronome oblíquo "me", que tem duas ocorrências e que o colocam na condição de objeto, tanto em "cochichavam-me" quanto em "me traziam"; o adjetivo "semelhante", que aproxima o menino do folheto, que é tão guenzo quanto ele; todos os grifos para as formas verbais no subjuntivo (lesse e explicasse), que, ainda que se reportem a um fato ocorrido, esfumam-se numa temporalidade passada imprecisa, que, por extensão, acabam por embaçar também o sujeito da ação, que fica ambiguamente diluído entre a primeira e a terceira pessoa.

Ora, sendo este o modo usual de João Cabral se expressar - e isso pode ser verificado até mesmo no livro A escola das facas-, causa espécie que ele tenha utilizado a primeira pessoa tão abertamente no poema "Autobiografia de um só dia". Pois após a descrição da cena e do ambiente que lhe confere uma tonalidade mórbida, através da qual o poema se expande, ele grafa o "eu" no seguinte dístico: "Nascemos eu e minha morte, / contra o ritual daquela Corte." E embora esta não tenha sido uma das portas de entrada mais frequentadas pela sua crítica, a morte ocupa na obra de João Cabral um papel determinante. Não só como o anúncio da indesejada das gentes, mas no plano simbólico ${ }^{5}$,

4 MELO NETO. Obra completa, p. 447.

5 Cf. SECCHIN. Poesia e desordem, p. 66. 
principalmente, como a negação do que é dado enquanto possibilidade, cujo registro mais explícito é perceptível já no título de sua obra mais conhecida e que se desdobra em inúmeros de seus poemas, inclusive naqueles que tematizam cemitérios pernambucanos e aqueles em que membros da família estão enterrados e que ultrapassam a fronteira do estado.

Ao grafar no mesmo verso "eu e minha morte", o poeta justapõe no mesmo plano o que lhe é próprio e o que é a sua negação, ambas as dimensões inscritas no mesmo espaço, que recebe a si e o seu reverso, ao contrário do que supostamente se elegeria como imagem única e acabada. Em vez disso, o que temos é um espaço carcomido pelas imagens de santo, esterilizado pela beatitude de gesso ou lírios e confrontado pela maré de mangues, onde explodem gritos e sangue, que passam a ser sua afirmação. Ao menos, o sangue de sua genealogia e o grito de sua dor, que agora são modalizados, se quisermos insistir no plano simbólico. Mais, o sangue aponta simultaneamente para sua carne e também para sua ancestralidade, ao passo que o grito revela apenas o desespero de uma voz cuja impostação é desafinada e talvez até vacilante, pelo contraditório que enseja.

De antemão, impõe-se a observação de que estamos lidando com um sujeito cujo olhar oscila entre o mangue para onde dá a janela do quarto de seu nascimento e a sombra dos antepassados, dada pela sua árvore genealógica. É dessa tradição familiar que advém o culto aos santos, com a religiosidade que lhe é inerente, sem poder evitar o nascimento dos filhos blasfemos, como é o caso. Assim, parece plausível aquela justaposição entre o sujeito e sua morte, já que a tradição católica nunca vai deixar de assombrá-lo. Em parte, pela formação escolar que teve em colégio marista (católico), mas sobretudo pela linhagem que o resguarda e que estava devidamente constituída no dia de seu nascimento.

A constituição daquele sujeito se faz, pois, na conjunção do que ele apresenta como sendo próprio, seu eu, e seu reverso, sua morte. Contra o que aquela corte nada sabia da singularidade de um homem, que é grito e esperneio. Suas blasfêmias, aliás, são seu próprio corpo: sangue e grito. Sangue do que ele é na sua constituição de sujeito venoso e também no que ele carrega de sangue azul da nobreza da terra. Grito do que há de revolta no seu discurso, mas também de medida. Medida essa que se confunde com sua própria voz, com a singularidade do sujeito que é e que não se conforma aos espaços que lhe foram dados, sejam geográficos ou sociais. Parido no quarto-dos-santos, sua sentença de condenação perpétua é estar atrelado - ainda que contra a vontade

6 Cf. GARCIA. Esfinge clara e outros enigmas, p. 230. 
- a um universo bem determinado, que se coloca diante dos seus olhos e não deixa de avivar o seu passado familiar, que coincide com o passado do próprio país, às vezes. Também por isso, quando olha para trás, não é só a casa dos avós que ele vê, mas também certa experiência, meio bizarra e meio jocosa, que não deixa de ter um valor histórico, simbolizado no poema pelo Engenho do Poço, de onde ele saiu para nascer, e, também, pelo casarão da Jaqueira onde ele nasceu.

\section{Memory, genealogy and subjectivity in João Cabral}

Abstract: The poem "Autobiografia de um só dia" was first published in the book A escola das facas in the early 1980s, when the author was already mature and recognized. There João Cabral de Melo Neto describes the circumstances of his birth under a "cloud of plaster" around the familiar apparatus. It is interesting therefore to investigate how the author constructs the idea of heaven, so we can relate his religious concept with familiar determinations, which become distinctive of his social place. From there, we can see how the matter that gave the resort his expression may be linked to their stylistic traits. Thus opens the possibility to approach as much as possible of his subjectivity, as in the poem in focus he expressed in the first person, fact absolutely episodic on his production that is characterized by objectivity and by third person.

Keywords: João Cabral de Melo Neto, Modern Brazilian poetry, Memory, Genealogy.

$$
\text { Referências }
$$

GARCIA, Othon Moacyr. Esfinge clara e outros enigmas. 2 ed. Rio de Janeiro: Topbooks 1996.

MELLO, Evaldo Cabral de. O nome e o sangue. 2 ed. Rio de Janeiro: Topbooks, 2000. MELO NETO, João Cabral de. Obra completa. Rio de Janeiro: Nova Aguilar, 1994. SECCHIN, Antonio Carlos. Poesia e desordem. Rio de Janeiro: Topbooks, 1996. VASCONCELOS, Selma. João Cabral de Melo Neto: retrato falado do poeta. Recife: Ed. do Autor, 2009. 